\title{
Modify Hitec molten salt and its properties tests by orthogonal experiment
}

\author{
Wei Zhai ${ }^{a}$, Bo Yang ${ }^{b}$, Maodong $\mathrm{Li}^{\mathrm{c}}$, Shiping $\mathrm{Li}^{\mathrm{d}}$, Mingliang Xin ${ }^{\mathrm{e}}$, \\ Jinmei Lin $^{f}$
}

Guangzhou Special Pressure Equipment Inspection and Research Institute, 510100 Guangzhou,
China

azhaiwei2014@126.com, bboycs@126.com, '2453962572@qq.com, d164354390@qq.com, e496738497@qq.com, 'gzspei@qq.com

Keywords: orthogonal experiment; modified Hitec molten salt; additive; properties.

\begin{abstract}
In this paper, by orthogonal experiment to modify Hitec molten salt in order to look for the optimum formulation molten salt which has good thermal properties. After that the melting point, latent heat of phase transformation, specific heat capacity, density, and thermal stability of the modified Hitec molten salt was characterized. The results showed that compare to Hitec molten salt, the optimum formulation molten salt showed low melting point, proper latent heat of phase transformation, greater heat of fusion, wide using temperature range and other advantages. The optimum formulation molten salt had good thermal properties and thermal stability. It has good application prospect in the aspect of high temperature heat storage/transfer.
\end{abstract}

\section{Introduction}

In the past decade, with the exacerbation of energy shortage around the world and the continuous increase in the level of greenhouse gas emissions, the use of various sources of renewable energy was increasingly important for sustainable development. Solar energy is becoming one of the most promising sources of energy. Among various technologies of solar energy, the solar thermal power plant has been considered as the most potential way[1-3] to massively utilize the solar energy in the future.

Thermal energy storage (TES) system plays a key role in solar thermal power plants by providing the ability to match the electrical output for peak and off-peak demands [4 -7]. Heat transfer fluids play a vital role in the TES system and solar thermal power plants. A huge amount of heat transfer fluids (even more than thousands tons) is usually required for carrying thermal energy in solar power plants and hence entails high capital investment cost. Therefore, the criterion of minimizing the cost whilst maximizing the heat transfer performance is a major pursuit for the selection of heat transfer fluids.

The industrial applications of molten salts are more and more widely [8-11]. Molten salts have unusual solvent properties which have led to their use in electrochemistry and metallurgical electrolysis. Meanwhile, molten salts have excellent heat transfer properties and have been considered to be used as transfer fluids in breeder reactors or fusion reactors, providing an increase in thermal efficiency which is made possible by their operations at high temperatures. At present, heat transfer medium in solar thermal power stations is usually used by potassium nitrate, sodium nitrate, sodium nitrite and their mixtures and they have been used successfully as thermal energy collection and storage fluid in a large-scale, solar central receiver demonstration system. According to phase diagrams [12], we find that Hitec molten salts consisting of $53 \% \mathrm{KNO} 3,40 \% \mathrm{NaNO} 2$ and $7 \% \mathrm{NaNO} 3$ have a lower melting point, $142^{\circ} \mathrm{C}$.In addition, this kind of molten salt has a higher operating temperature range at the same pressure and lower vapor pressure, and thermal conductivity is double that of other organic heat transfer fluids. Unfortunately, this kind of molten salt is not stable enough at a higher temperature in the presence of oxygen, and the melting point of rising molten lead to 
deterioration of the phenomenon. But researchers working on low melting point, heat of fusion large, wide temperature range, and good thermal stability of molten salt.

In this paper, additive- $\mathrm{A}$, additive- $\mathrm{B}$ and additive- $\mathrm{C}$ as factors for orthogonal experiment, then the orthogonal experiment that modify Hitec molten salt was designed. In order to look for the optimum formulation molten salt which has good thermal properties. The melting point, latent heat of phase change, and thermal stability of the optimum formulation molten salt were characterized.

\section{Experimental}

According to the research and related literatures of the hitec molten. In this paper, additive-A, additive-B and additive- $\mathrm{C}$ as factors for orthogonal experiment, Levers of factor orthogonal experiment are shown in Table1-1, design L8 $\left(2^{3}\right)$ orthogonal experiment table are shown in Table 1-2. A class of molten salt mixtures made of additive- $A$, additive- $B$, additive- $C$ and Hitec molten salt are identified.

Table 1-1 Factors and levers for orthogonal experiment

\begin{tabular}{c|ccc}
\hline Levers & $\begin{array}{c}\mathrm{A} \\
\text { Factors }\end{array}$ & $\begin{array}{c}\mathrm{B} \\
\text { additive-A (mass } \%)\end{array}$ & $\begin{array}{c}\mathrm{C} \\
\text { additive-B (mass } \%)\end{array}$ \\
\hline 1 & 2 & 2 & 1 \\
2 & 4 & 4 & 2 \\
\hline
\end{tabular}

Table 1-2 Orthogonal experiment table

\begin{tabular}{cccc}
\hline $\begin{array}{c}\text { The serial } \\
\text { number }\end{array}$ & A & B & C \\
additive-A (mass $\%)$ & additive-B (mass $\%)$ & additive-C (mass $\%$ ) \\
\hline 1 & 4 & 4 & 1 \\
3 & 4 & 4 & 1 \\
4 & 2 & 4 & 2 \\
5 & 4 & 2 & 1 \\
6 & 4 & 2 & 2 \\
7 & 2 & 4 & 2 \\
8 & 2 & 2 & 1 \\
\hline
\end{tabular}

Besides, Thermogravimetry-Differential Scanning Calorimetry instrument STA-409PC produced by German NETZSCH Company, was used to measure molten salt's melting point and latent heat of molten salts. The molten specific heat was measured by DSC. The measurements conditions for the sample, the reference (a sample with a known specific heat capacity, for example, sapphire) and the empty pan were the same. The specific heat capacity of the sample was calculated by Eq. (1) from the DSC data obtained.

$$
C p_{s}=\frac{H m_{r}}{h m_{s}} C p_{r}
$$

where $C p_{s}$, specific heat capacity of sample $(\mathrm{kJ} / \mathrm{kg} \mathrm{K}), \mathrm{Cp}_{\mathrm{r}}$, specific heat capacity of reference $(\mathrm{kJ} / \mathrm{kg} \mathrm{K}), \mathrm{m}_{\mathrm{s}}$, mass of sample $(\mathrm{kg}), \mathrm{m}_{\mathrm{r}}$, mass of reference $(\mathrm{kg}), \mathrm{H}$,DSC temperature difference of sample and empty pan, h, DSC temperature difference of reference and empty pan.

Density was gained by Archimedes theory in RSD-06 synthetic test instrument for the physical characteristics of fused object. In order to investigate the decomposition of molten salts, the weight of the samples was measured at $450^{\circ} \mathrm{C}, 500^{\circ} \mathrm{C}, 550^{\circ} \mathrm{C}, 600^{\circ} \mathrm{C}$. In addition, Microwave Command Guidance System was used to measure molten salts thermal cycling. 


\section{Results and discussion}

\subsection{Melting point and latent heat of molten salt mixtures for orthogonal experiment}

In Fig.1-1 and Fig.1-2 show that DTA profile of molten salt mixtures sample Hitec 1-4, Hitec 5-8.

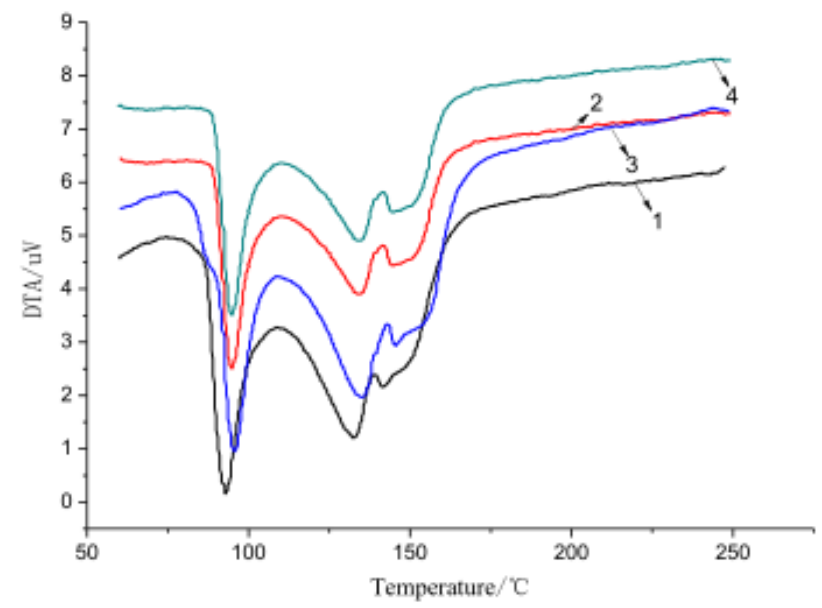

Fig.1 DTA profile of mixture molten salt sample Hitec 1-4

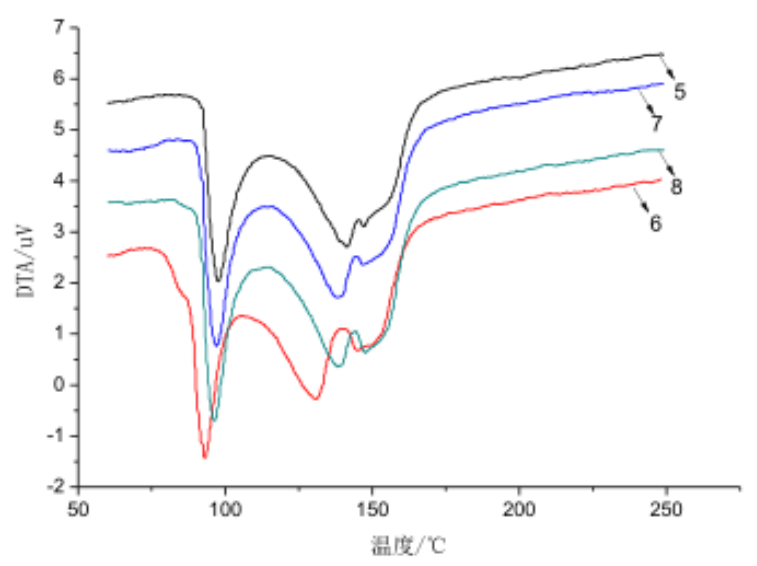

Fig.2 DTA profile of mixture molten salt sample Hitec 5-8

\subsection{The results analysis of orthogonal experiment}

The melting point and latent heat of the mixed molten salt is evaluation. The orthogonal experimental results are shown in Table 1-3 and visual analysis of the results were shown in Table $1-4$.

Table 1-3 Orthogonal experiment results table

\begin{tabular}{cccccc}
\hline $\begin{array}{c}\text { The serial } \\
\text { number }\end{array}$ & $\begin{array}{c}\text { A } \\
\text { additive-A } \\
(\text { mass\% })\end{array}$ & $\begin{array}{c}\mathrm{B} \\
\text { additive-B } \\
(\text { mass\%) }\end{array}$ & $\begin{array}{c}\mathrm{C} \\
\text { additive-C } \\
(\text { mass\%) }\end{array}$ & $\begin{array}{c}\text { melting point } \\
\left({ }^{\circ} \mathrm{C}\right)\end{array}$ & $\begin{array}{c}\text { latent heat } \\
(\mathrm{J} / \mathrm{g})\end{array}$ \\
\hline 1 & 4 & 4 & 1 & 116.1 & 59.32 \\
2 & 4 & 4 & 2 & 119.2 & 56.13 \\
3 & 2 & 4 & 1 & 120.7 & 61.64 \\
4 & 4 & 2 & 2 & 119.7 & 65.05 \\
5 & 4 & 2 & 1 & 125.3 & 67.19 \\
6 & 2 & 4 & 2 & 115.6 & 61.39 \\
7 & 2 & 2 & 2 & 121.7 & 64.81 \\
8 & 2 & 2 & 1 & 120.6 & 70.32 \\
\hline
\end{tabular}


Table 1-4 Results of orthogonal experiment by direct-viewing analysis

\begin{tabular}{|c|c|c|c|c|}
\hline $\begin{array}{l}\text { Factors } \\
\text { standard }\end{array}$ & & $\begin{array}{c}\text { A } \\
\text { additive-A } \\
(\operatorname{mass} \%)\end{array}$ & $\begin{array}{c}\text { B } \\
\text { additive-B } \\
(\operatorname{mass} \%)\end{array}$ & $\begin{array}{c}\mathrm{C} \\
\text { additive-C } \\
(\operatorname{mass} \%)\end{array}$ \\
\hline $\begin{array}{l}\text { melting } \\
\text { point } \\
\left({ }^{\circ} \mathrm{C}\right)\end{array}$ & $\begin{array}{c}\mathrm{K} 1 \\
\mathrm{~K} 2 \\
\text { range } \mathrm{R} \\
\text { primary factor } \\
\text { optimal plan } \\
\end{array}$ & $\begin{array}{c}159.9 \\
160.1 \\
0.2\end{array}$ & $\begin{array}{c}162.8 \\
157.2 \\
5.6 \\
\text { B C A } \\
\text { B2C } 2 \text { A } 1 \\
\end{array}$ & $\begin{array}{c}161.3 \\
158.7 \\
2.6\end{array}$ \\
\hline $\begin{array}{l}\text { Latent } \\
\text { heat } \\
(\mathrm{J} / \mathrm{g})\end{array}$ & $\begin{array}{c}\mathrm{K} 1 \\
\mathrm{~K} 2 \\
\text { range } \mathrm{R} \\
\text { primary factor } \\
\text { optimal plan }\end{array}$ & $\begin{array}{c}85.32 \\
82.56 \\
2.76\end{array}$ & $\begin{array}{c}88.39 \\
79.49 \\
8.9 \\
\text { BCA } \\
\text { B1C1A } 1\end{array}$ & $\begin{array}{c}85.42 \\
82.46 \\
2.8\end{array}$ \\
\hline
\end{tabular}

The evaluation of various factors corresponding to range $\mathrm{R}$ can be seen in Table 1-4. Various factors on effect sizes of the melting point, latent heat are as follows:

Melting point: $\mathrm{B}>\mathrm{C}>\mathrm{A}$

Latent heat: $\mathrm{B}>\mathrm{C}>\mathrm{A}$

The integrated and balanced approach be used to analyze various factors.

For factor $A$ : for the melting point can be selected $A_{1}, A_{2}$, for the latent heat can be selected $A_{1}$. $A$ factor taken into account for effect size of the melting point, the latent heat. The comprehensive considerations can select $\mathrm{A}_{1}, \mathrm{~A}_{2}$.

For factor $\mathrm{B}$ : for the melting point can be selected $\mathrm{B}_{2}$, for the latent heat can be selected $\mathrm{B}_{1}$. $\mathrm{A}$ factor taken into account for effect size of the melting point, the latent heat. The comprehensive considerations can select $\mathrm{B}_{1}$.

For factor $\mathrm{C}$ : for the melting point can be selected $\mathrm{C}_{2}$, for the latent heat can be selected $\mathrm{C}_{1}$. $\mathrm{A}$ factor taken into account for effect size of the melting point, the latent heat. The comprehensive considerations can select $\mathrm{C}_{1}$.

Through comprehensive analysis can determine the optimum formulation is $\mathrm{A}_{1} \mathrm{~B}_{1} \mathrm{C}_{1}$. It melting point is $120.6^{\circ} \mathrm{C}$ and latent heat is $70.32 \mathrm{~J} / \mathrm{g}$. The results showed that compare to Hitec molten salt (melting point is $142^{\circ} \mathrm{C}$ and latent heat is $58.52 \mathrm{~J} / \mathrm{g}$ ), the melting point of the optimum formulation molten salt is reduced about $21^{\circ} \mathrm{C}$, the latent heat increase of $20.2 \%$.

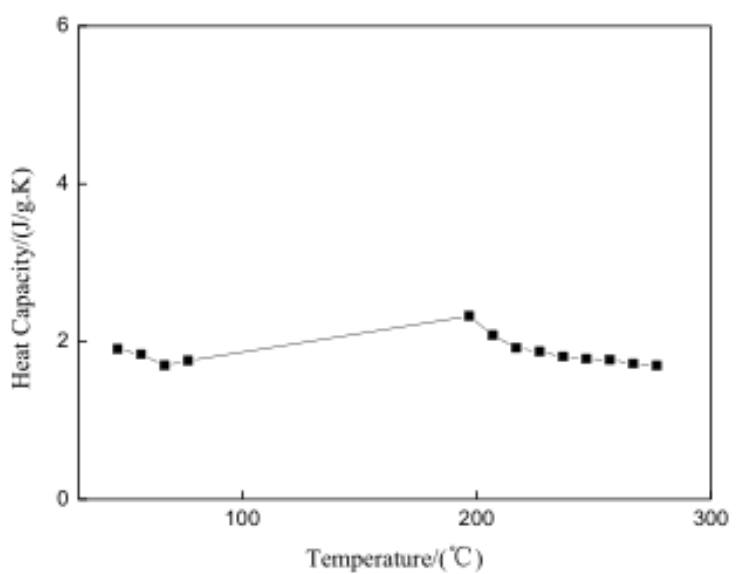

In Figure 3. Heat capacity curve of the optimum formulation molten salt 


\subsection{Heat capacity of the optimum formulation molten salt}

Figure 3 shows the heat capacity curve of the optimum formulation molten salt. The heat capacity data for this molten salt in the solid state in the temperature range of 46.85 to $76.85^{\circ} \mathrm{C}$ showed linear slightly reduce with temperature increasing. The heat capacity data for this molten salt in the liquid state in the temperature range of 196.85 to $276.85^{\circ} \mathrm{C}$ showed a downward trend. The heat storage capacity of the optimum formulation molten salt is desirable.

\subsection{Density of the optimum formulation molten salt}

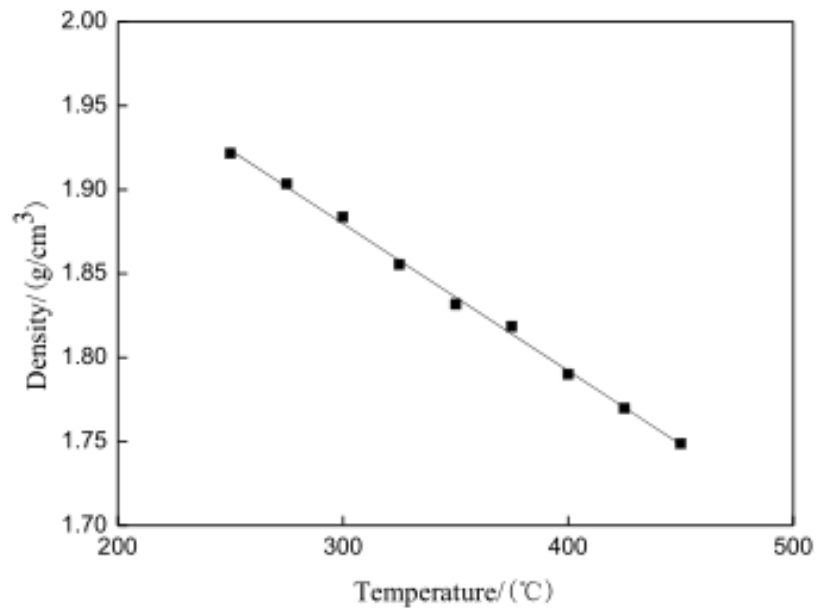

In Figure 4. Density curve of the optimum formulation molten salt

The density of the optimum formulation molten salt as function of temperature is plotted in Figure 4. The density test was conducted at above the molten salt melting point. In the liquid state the density has linearly dependence with temperature [13], which can be expressed as $\mathrm{q}=\mathrm{A}-\mathrm{Bt}$. The regression analysis is performed to determine the coefficients $\mathrm{A}$ and $\mathrm{B}$ of the optimum formulation molten salt. The results obtained for $A$ and $B$ are $2.1429 \mathrm{~g} / \mathrm{cm}^{3}$ and $0.9 \times 10^{-3}{ }^{\circ} \mathrm{C}$, respectively.

\subsection{Thermal stability of the optimum formulation molten salt}

Figure 5 shows that the weight of the optimum formulation molten salt at different temperatures and time. At $500^{\circ} \mathrm{C}$ and $550^{\circ} \mathrm{C}$ for $30 \mathrm{~h}$, the weight loss in the optimum formulation molten salt was $0.525 \%, 5.1 \%$, respectively. The reslut showed that the optimum formulation molten salt was stable below $550^{\circ} \mathrm{C}$. However the rate of decomposition for this molten salt would gradually increase at above $550^{\circ} \mathrm{C}$. Therefore, the molten salt have good thermal stability in $550{ }^{\circ} \mathrm{C}$.

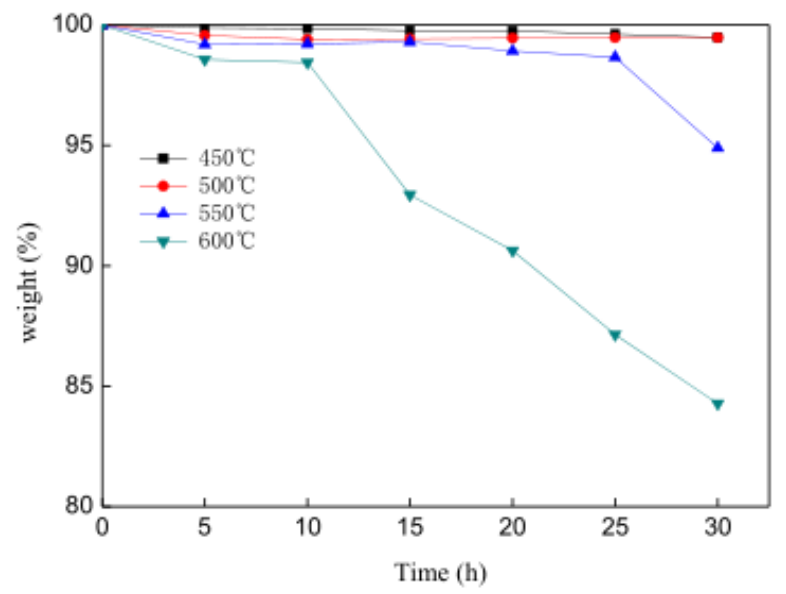

In Figure 5. Weight change for various temperature and time for the optimum formulation molten salt 


\section{Conclusions}

In this paper, additive- $\mathrm{A}$, additive- $\mathrm{B}$ and additive- $\mathrm{C}$ as factors for orthogonal experiment, then the orthogonal experiment that modify Hitec molten salt was designed. In order to look for the optimum formulation molten salt which have good thermal properties. The melting point of the optimum formulation molten salt is $120.6^{\circ} \mathrm{C}$ and latent heat is $70.32 \mathrm{~J} / \mathrm{g}$. It showed low melting point, proper latent heat of phase transformation, a larger specific heat capacity and other advantages. And it has good thermal stability at a high temperature. Therefore the optimum formulation molten salt has the very good application prospect in the aspect of high temperature heat storage/transfer.

\section{Acknowledgements}

This work was financially supported by heat transfer of energy-saving single tank thermocline molten salt thermal storage system and general administration of quality supervision, inspection and quarantine of the people's republic of china.

\section{References}

[1] J. Badcock, M. Lenzen, Subsidies for electricity-generating technologies: a review, Energy Policy 38 (9) (2010) 5038-5047.

[2] M. Thirugnanasambandam, S.Iniya $n$, R. Goic, A review of solar thermal technologies, Renewable and Sustainable Energy Reviews 14 (1) (2010) 312-322.

[3] K.H. Solangi, et al., A review on global solar energy policy, Renewable and Sustainable Energy Reviews 15 (4) (2011) 2149-2163

[4] U. Herrmann, D.W. Kearney, Survey of thermal energy storage for parabolic trough power plants, Journal of Solar Energy_-Transcations of ASME 124 (2)(2002) 145-152.

[5] R. Tamme, D. Laing, W.-D. Steinmann, 2003. Advanced thermal energy storage technology for parabolic trough, In: asme conference proceedings, 2003, 36762, pp. 563-571

[6] H. Michels, R. Pitz-Paal, Cascaded latent heat storage for parabolic trough solar power plants, Solar Energy 81 (6) (2007) 829-837

[7] A. Hoshi, et al, Screening of high melting point phase change materials (PCM) in solar thermal concentrating technology based on CLFR, Solar Energy 79 (3) (2005) 332-339aaa

[8] Johnson Winford B, Nagle Wesley M. Circulating HTS as a Pilot Plant Heat Transfer Medium. Industrial \& Engineering Chemistry, 1947, 39(8): 971-974.

[9] Mills David. Advances in solar thermal electricity technology. Solar energy, 2004, 76(1): 19-31.

[10] Kamimoto Masayuki, Tanaka Tadayoshi, Tani Tatsuo, et al. Investigation of nitrate salts for solar latent heat storage. Solar Energy, 1980, 24(6): 581-587.

[11] Oró E, Gracia A, Castell A, Farid MM, Cabeza LF. Review on phase change materials (PCMs) for cold thermal energy storage applications. Apply Energy 2012; 99: 513-33.

[12] Reg. U. S, Pat. \&Tm. Off. HITE heat transfer salt. Brenntag Company, 1-10.

[13] Nasch PM, Steinmann SG. Density and thermal expansion of molten manganese, iron, nickel, copper, aluminum and tin by means of the gamma-ray attenuation technique. Phys Chem Liq 1995; 29: 43-58. 